\title{
A Laboratory Device for Continual Measurement of Water Retention and Shrink/Swell Properties during Drying/Wetting Cycles
}

\author{
Guifang Qi and Jean-Charles Michel ${ }^{1}$ \\ Agrocampus Ouest, Centre d'Angers, Unité de Recherche EPHOR, \\ Environnement Physique de la plante Horticole, 2, rue Le Nôtre, 49045 \\ Angers Cedex 01, France \\ Pascal Boivin \\ HES-SO Genève, HEPIA, 150 route de Presinge, 1254 Jussy, Switzerland
}

\section{Sylvain Charpentier}

Agrocampus Ouest, Centre d'Angers, Unité de Recherche EPHOR, Environnement Physique de la plante Horticole, 2, rue Le Nôtre, 49045 Angers Cedex 01, France

Additional index words. void ratio, water ratio, hysteresis, growing media, peat

\begin{abstract}
The precise measurement of the water retention and shrink/swell properties of growing media or soil over time is important for the effective management of irrigation and fertilization. A new apparatus was developed for simultaneously and continuously measuring the water retention and shrink/swell properties of growing media during several drying/wetting cycles with varying intensities $(0 \leftrightarrow-5 \mathrm{kPa}, 0 \leftrightarrow-10 \mathrm{kPa}, 0 \leftrightarrow-32$ $\mathrm{kPa}$ ). The measurements on slightly decomposed Sphagnum peat showed encouraging results. Regardless of the intensity of drying, water retention and shrink/swell properties are mainly modified after the first drying process, resulting in degradation of density and water retention, whereas these properties are unaffected by the other cycles, even if hysteresis phenomena are always shown to take place. Variations in drying intensity reveal different physical behaviors with an inflection point observed (i.e., a change in physical behavior) for the shrink/swell and water retention curves for the highest intensity tested (from $-20 \mathrm{kPa}$ ).
\end{abstract}

Soil physics studies usually include two complementary aspects: 1) soil solid phase organization; and 2) transport processes. The water retention, $\Psi(\theta)$, and hydraulic conductivity curves, $K(\Psi)$ or $K(\theta)$, are usually measured to characterize the water transport in a soil system with reference to matric potential. Similarly, the shrinkage (or swelling) curve, $e(\theta)$, is measured to characterize the changes in the soil solid phase organization. Two approaches are commonly used to determine the soil volumetric water content, $\theta$, and water potential relationships, $\Psi(\theta)$ : the discontinuous approach that uses sand table and pressure cells to determine the equilibrium water content at a certain pressure head and the continuous approach that uses paired sensors such as time domain reflectometry and tensiometers to simultaneously determine water content and matric potential in the same soil volume under equilibrium assumption

Received for publication 1 Apr. 2011. Accepted for publication 17 July 2011.

We thank Y. Barraud-Roussel, D. Lemesle, and F. Lamy for their technical assistance and Gail Wagman for reviewing the manuscript.

${ }^{1}$ To whom reprint requests should be addressed; e-mail jean-charles.michel@agrocampus-ouest.fr.
(Jury and Horton, 2004; Warrick, 2002). The $\Psi(\theta)$ relationships established by water desorption or absorption are not identical in most cases; this is referred to as the hysteresis. Despite the importance of hysteresis in modeling soil water transport, suitable measurement techniques are severely lacking at this time.

The shrink/swell $e(\theta)$ curve can also be measured by continuous or discontinuous methods. With the discontinuous approach, the shrinkage curve is usually determined from volume and water content data measured on series of soil clods (Crescimanno and Provenzano, 1999; Tariq and Durnford, 1993). To increase knowledge about soil shrinkage behavior, continuous measurement of shrinkage curves on undisturbed core samples using a displacement transducer and an electronic balance was proposed by Braudeau (1987) and Braudeau et al. (1999) and adapted by Boivin et al. (2004) for simultaneous determination of $\Psi(\theta)$. As for $\Psi(\theta)$, changes in pore and total volumes were most of the time analyzed during the drying process. Although the shrink/swell properties can be one of the causes of hysteresis phenomena, few authors have measured soil swelling during a wetting process. For example, Michel et al. (2000) described the swelling properties of clay soil samples in the laboratory, and Favre et al. (1997) measured clay swelling behavior in situ.

Like in soil studies, the physical properties of growing media used in horticulture are usually characterized by the water retention curve obtained during a drying process according to standardized procedures, for example, the European standard, NF EN 13041 (2000). However, water content in growing media changes more frequently and more strongly than in soil during a growing season as a result of their limited volume (pot, container). Consequently, the physical properties of growing media that have undergone many drying/ rewetting cycles should change more radically, resulting in variations in water and air availability for the plants that may be considerable. Some previous works (Bougoul et al., 2005; da Silva et al., 1995; Naasz et al., 2005; Wallach et al., 1992) aimed at evaluating the growing media (organic or mineral) properties during a drying/wetting cycle. These experiments pointed out the need for additional detailed observation on the hysteretic behavior for determining growing media quality. Frequent changes in the water content of growing media could influence water retention properties as well as solid phase organization (shrinkage/swelling) (Fonteno et al., 1981; Gruda and Schnitzler, 2004; Heiskanen, 1995; Michel et al., 2004a) and wettability for some organic substrates (Michel et al., 2004b; Michel et al., 2001; Naasz et al., 2008; Valat et al., 1991). This can, respectively, lead to changes in total porosity volume and pore connectivity, on the one hand, and the difficulty to rewet on the other and could then be considered as potential causes of hysteretic phenomena in a porous media (Horgan and Ball, 2005; Naasz et al., 2008).

In this study, we therefore adopted the method developed by Boivin et al. (2004) for simultaneous and continuous measurements of water retention and shrinkage/swelling curves and adapted it to the measurement of drying/wetting cycles with different drying intensities.

\section{Materials and Methods}

Principle and description of the experimental set-up. The experiment is based on the method previously developed by Boivin et al. (2004) for shrinkage curve determination during a free drying process. This method was adapted using instruments to allow soil sample drainage and refilling with the control of drying and wetting cycles between different pressure intensities. The set-up is illustrated in Figure 1.

The experiment was performed in a climatic chamber at $20{ }^{\circ} \mathrm{C}$. Sample height $(h)$, weight $(w)$, and pressure head $(\psi)$ were simultaneously recorded every minute during drying and rewetting cycles using a linear variable differential transducer (LVDT; AMETEK, Elancourt, France), a balance (PL1502-S/03; Mettler Toledo, Viroflay, France $)$, and a ceramic cup $(2.2 \times 20 \mathrm{~mm}$; 
SDEC 220, Reignac sur Indre, France) inserted at the center of the sample and connected to a pressure transmitter (GE Druck PTX Ex01269; DRUCK Limited, Leicester, UK), respectively.

To control the drying/wetting cycles, a DIY ceramic support was placed at the bottom of the sample. This support is capable of maintaining water pressure and draining or injecting water from or into the sample. It consisted of a thin reservoir made of transparent Plexiglas with two outlets and a hermetically attached porous ceramic plate $(96 \times$ 6 mm; SDEC 9600, Reignac sur Indre, France). The support acts as a mini-suction table as commonly used for water retention curve determination. However, with a 1.5-bar air entry pressure, it allows applying much greater pressure than the sand table and can theoretically reach a suction of up to $-95 \mathrm{kPa}$, because water boils at $20{ }^{\circ} \mathrm{C}$ under this pressure. However, as a result of the contact restrictions between the substrate sample and the ceramic plate, measurements could only be carried out in the water potential range of between 0 and $-70 \mathrm{kPa}$. One of the support outlets was connected to a rigid water reservoir with regulated and buffered pressure; the other was connected to a pressure transmitter for pressure monitoring.

The switch between drying and wetting cycles was controlled by a solenoid, which was connected to an adjustable vacuum pump to apply the desired suction. When the pressure head measured in the sample reached the lower threshold established for the experiment, the solenoid was closed and then applying suction was stopped so that the pressure of the ceramic support began to slowly rise to atmospheric pressure and the sample began to be rewetted. In contrast, once the pressure head in the sample reached the upper threshold, the solenoid was opened and the suction began.
Compact FieldPoint (National Instruments, Nanterre, France), a data acquisition instrument, was used to collect data and to control the solenoid. A LabVIEW (National Instruments) program was developed for experimental control. The upper and lower thresholds and the number of cycles were the initial inputs for this program. Tests were then carried out automatically.

Sample preparation. The experiments were conducted on a fine ( 0 to $\approx 10 \mathrm{~mm}$ ) and slightly decomposed sphagnum peat from Ireland, chosen because this type of peat is considered to be a main reference substrate and widely used for horticulture worldwide $[\approx 60 \%$ per volume used as growing media in Europe (Schmilewski, 2009)]. The main characteristics of sphagnum peat are given in Table 1 . The samples were prepared according to the European standardized procedure, NF EN 13041 (2000). A large polyvinyl chloride (PVC) cylinder (diameter: $14 \mathrm{~cm}$; height: $14 \mathrm{~cm}$ ) was manually filled with the substrate, slowly wetted $(30 \mathrm{~min})$ from the bottom, saturated for $24 \mathrm{~h}$, and then allowed to equilibrate to a water potential of $-5 \mathrm{kPa}$ for $48 \mathrm{~h}$. The substrates were then removed from the cylinder and homogenized for use in the experiment.

They were then manually placed without packing in smaller PVC cylinders (diameter: $10 \mathrm{~cm}$; height: $5 \mathrm{~cm}$ ), slowly rewetted from the bottom, and saturated for $24 \mathrm{~h}$. A plastic cover was placed on the sample to limit the evaporation effect.

Experimental procedure and data treatment. The experiments were performed for three cycles for intensities of between 0 and $-5 \mathrm{kPa}, 0$ and $-10 \mathrm{kPa}$, and 0 and $-31.6 \mathrm{kPa}$ to study the effects of suction intensities and number of cycles.

The changes in sample height were measured by the transducer and then converted

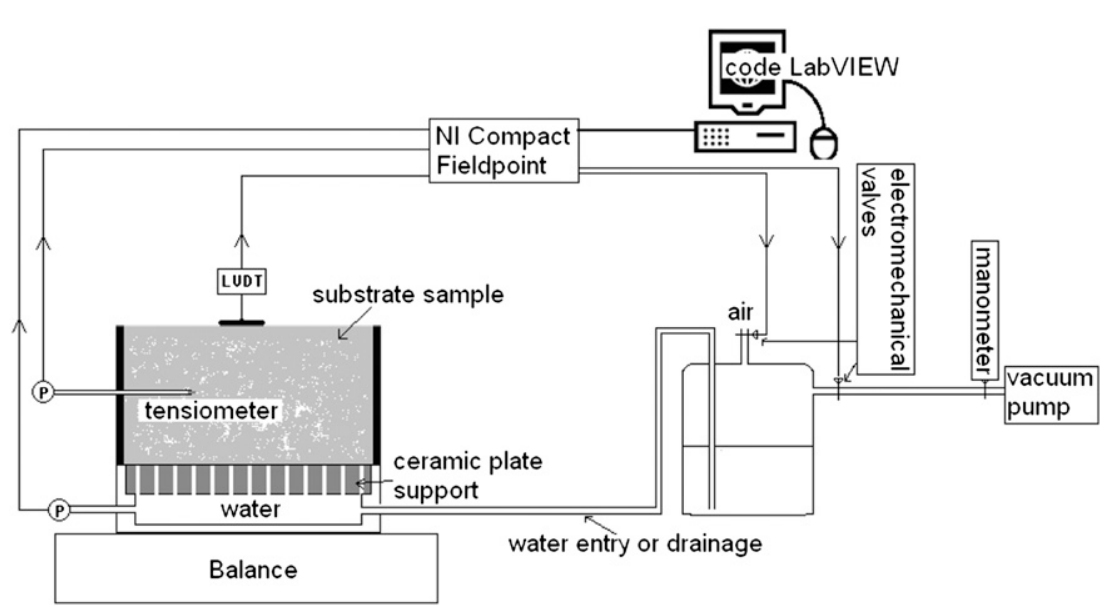

Fig. 1. Experimental device used for measuring water retention and shrink/swell properties during drying/ wetting cycles. into sample volume using the following equation (Bronswijk, 1990):

$$
\frac{V}{V_{0}}=\left(\frac{h}{h_{0}}\right)^{n}
$$

with:

$$
n=\log \left(\frac{V_{f}}{V_{0}}\right) / \log \left(\frac{h_{f}}{h_{0}}\right)
$$

where $V_{0}, V_{\mathrm{f}}, V, h_{0}, h_{\mathrm{f}}$, and $h$ are the volumes and the heights of the sample at the beginning, at the end, and during the experiment, respectively, and $n$ is the geometric factor. In this experiment, we assumed that the substrate deformation was isotropic. Therefore, $n=3$ was used to calculate the volume changes, according to Boivin (2007).

At the same time, water contents were calculated from weight recorded during the experiments and from the dry weight of the substrate determined at $105{ }^{\circ} \mathrm{C}$ at the end of the experiment. Shrinkage and swelling properties of the materials were expressed with the void ratio $e=V_{\mathrm{v}} / V_{\mathrm{s}}$ and the water ratio $\mathrm{v}=$ $V_{\mathrm{w}} / V_{\mathrm{s}}$, where $V_{\mathrm{v}}, V_{\mathrm{w}}$, and $V_{\mathrm{s}}$ are the void, water, and solid volumes, respectively. To do this, the solid volume was calculated from its density measured by a pycnometer and the dry mass $\left(105^{\circ} \mathrm{C}\right)($ Table 1$)$, whereas the void volume was determined by subtracting the solid volume from the total volume.

A minimum of three repetitions was carried out to establish a mean curve. This curve was adjusted by using a modified van GenuchtenDurner model for a multimodal porosity approach (Durner, 1994; Van Genuchten, 1980). The water retention expression thus assumes the following form:

$$
\begin{aligned}
& \frac{v-v_{\min }}{v_{\max }-v_{\min }}=\sum_{i=1}^{k} w_{i}\left(1+\left(\alpha_{i} \psi\right)^{n_{i}}\right)^{-m_{i}} \\
& 0<w_{\mathrm{i}}<1 \text { and } \Sigma w_{\mathrm{i}}=1
\end{aligned}
$$

where $v$ is the water ratio $\left(\mathrm{m}^{3} \cdot \mathrm{m}^{-3}\right) ; v_{\min }$ and $v_{\max }$ are the minimal water ratio and the water ratio at saturation $\left(\mathrm{m}^{3} \cdot \mathrm{m}^{-3}\right) ; \psi$ represents the pressure head $(\mathrm{kPa}) ; k$ is the number of subsystems, equal to 2 for our study; $w_{\mathrm{i}}$ represents the weighting factors of the total pore space fraction to be attributed to the $i$ th subcurve; and $\alpha_{i}, n_{\mathrm{i}}$, and $m_{\mathrm{i}}$ are fitting parameters for each of the partial curves.

On the basis of the works of Boivin et al., (2006) and Peng and Horn (2005), who attempted to model the shrinkage curve with a mathematical expression similar to that of Van Genuchten (1980), we presented the curves $e(\psi)$ with the same approach.

On the basis of the points $v(\psi)$ or $e(\psi)$, a mean curve was fitted on each section corresponding to one drying or one wetting process with a nonlinear least-squares optimization (by using Excel Solver). For exam-

\begin{tabular}{|c|c|c|c|c|c|c|c|}
\hline \multirow{2}{*}{$\begin{array}{l}\text { Physicochemical } \\
\text { characteristics }\end{array}$} & \multirow[b]{2}{*}{$\mathrm{pH}$} & \multirow{2}{*}{$\frac{\text { Electrical conductivity }}{\left(\mathrm{mS} \cdot \mathrm{cm}^{-1}\right)}$} & \multirow{2}{*}{$\frac{\text { Cation exchange capacity }}{\left(\mathrm{cmol} \cdot \mathrm{kg}^{-1}\right)}$} & \multirow{2}{*}{$\frac{\text { Carbon }}{(\%)}$} & \multirow{2}{*}{$\frac{\text { Nitrogen }}{(\%)}$} & Solid density & Bulk density \\
\hline & & & & & & \multicolumn{2}{|c|}{$\left(\mathrm{g} \cdot \mathrm{cm}^{-3}\right)$} \\
\hline
\end{tabular}
ple, curves shown on Figures 2, 3, and 4 result from six sections (first drying, first wetting,

Table 1. Main characteristics of sphagnum peat studied. 


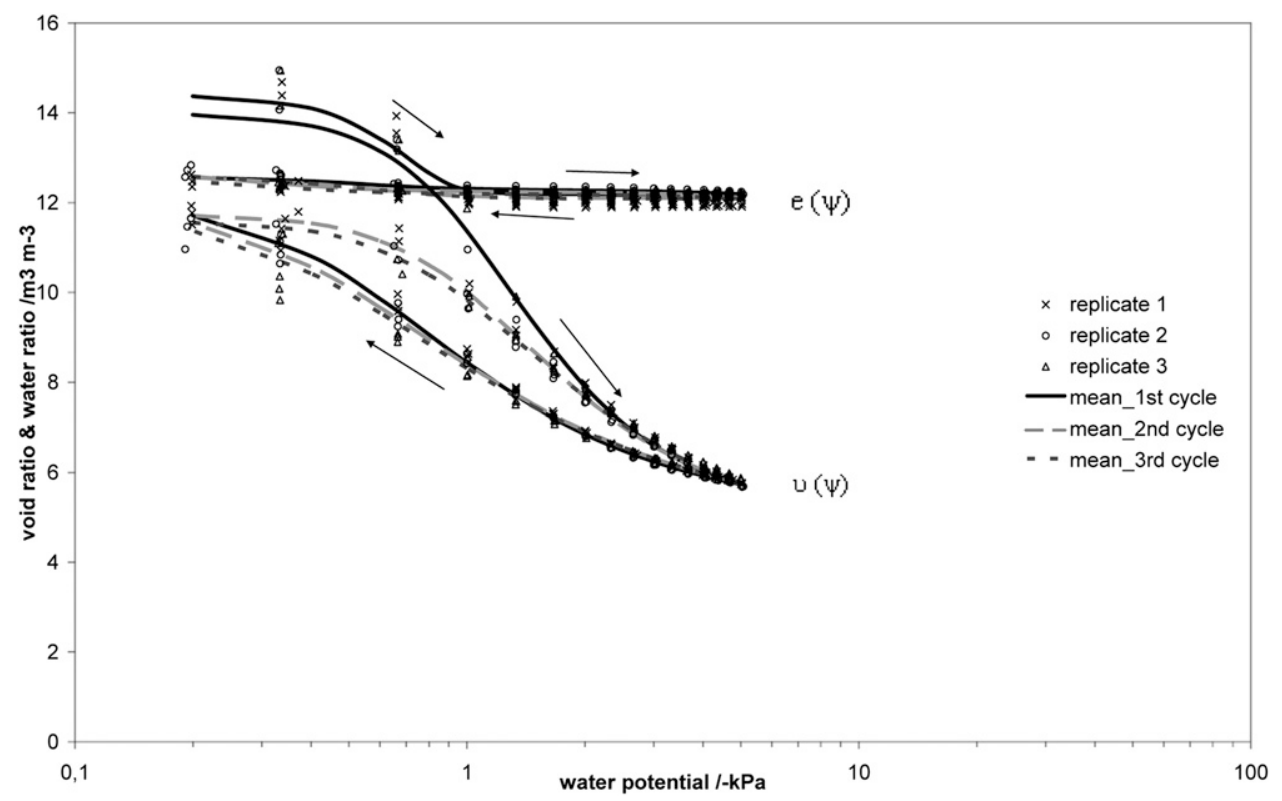

Fig. 2. Water $(v)$ and void $(e)$ ratios as a function of water potential during three drying/wetting cycles between -0.2 and $-5 \mathrm{kPa}$.

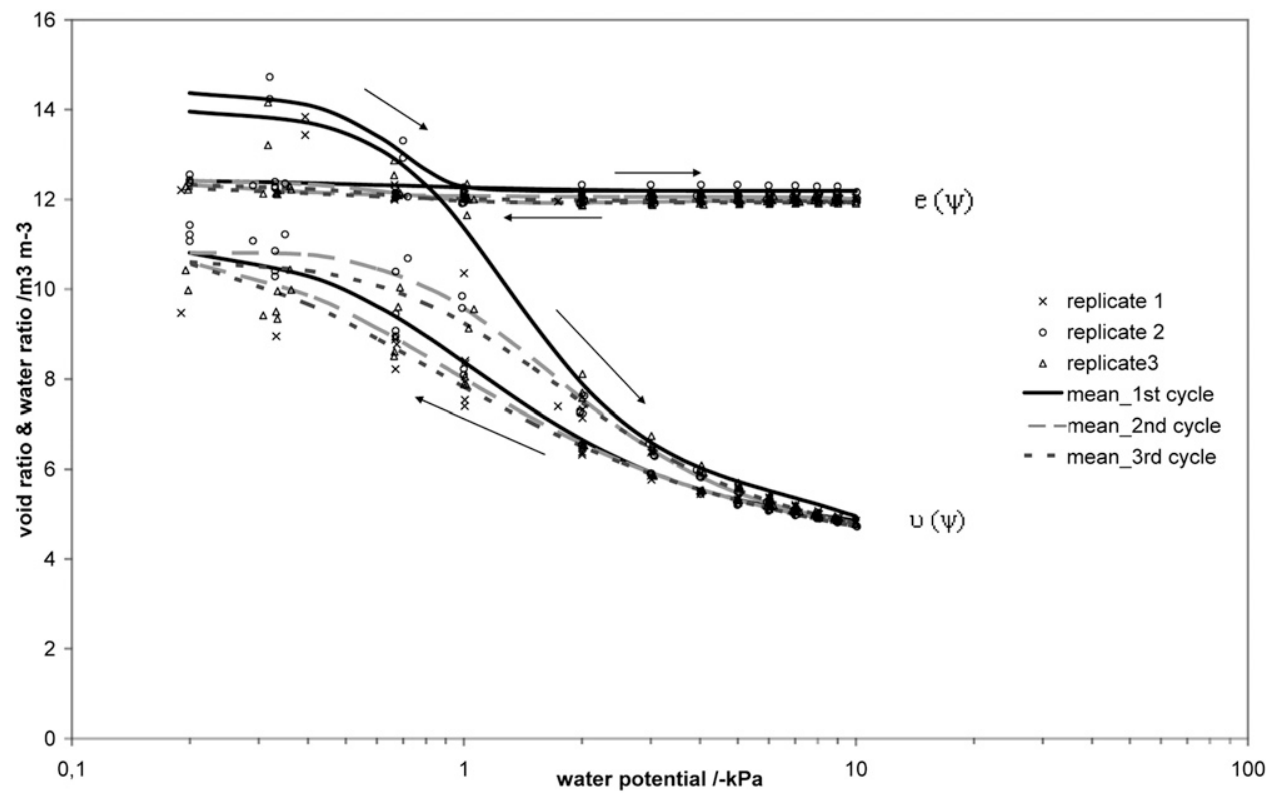

Fig. 3. Water (v) and void (e) ratios as a function of water potential during three drying/wetting cycles between -0.2 and $-10 \mathrm{kPa}$.

second drying, second wetting, third drying, and third wetting) for three cycles.

\section{Results and Discussion}

Reproducibility of the method. Figures 2, 3 , and 4 represent measured data and the mean curves obtained from three replicates for three drying/wetting cycles with three different intensities. For $v(\psi)$ curves, the difference between each replicate was not significant, except for measured values near water saturation. These deviations near saturation may be the result of the accuracy of the pressure head measurements, which is $0.16 \%$ of measured absolute pressure. The fitting parameters and coefficient of determination, $r^{2}$, for $v(\psi)$ curves are presented in Table 2 . The coefficients of determination, $r^{2}$, were higher than 0.98 , except for the first and second wetting curves as of $-32 \mathrm{kPa}$.

For $e(\psi)$ curves, the differences between measured values for each replicate and mean data do not exceed $5 \%$. In contrast to $v(\psi)$, these deviations are almost similar for more or less wet conditions. However, in the case of our studied samples, the void ratio, $e$, is almost constant, whereas the pressure head, $\psi$, changes after the first initial shrinkage (as shown in Figs. 2, 3, and 4), and the values and calculations of $r^{2}$ are of no interest as is the case for the fitting parameters that can widely vary without changing the adjusted mean curve.
Behavior of the sample studied. The water retention and shrinkage/swelling properties were measured during three drying/wetting cycles with intensities varying between -0.2 and $-5 \mathrm{kPa},-0.2$ and $-10 \mathrm{kPa}$, and -0.2 and $-32 \mathrm{kPa}$ with the objective of determining how physical properties are affected by the moisture content history. Results are presented by water and void ratio evolutions as a function of water potential, as illustrated in Figures 2, 3, and 4, respectively.

Effects of the number of drying/wetting cycles. Regardless of the drying intensities tested, the measurements showed differences between the first and the second cycles, whereas physical behaviors for the second and the third cycles were quite similar. 


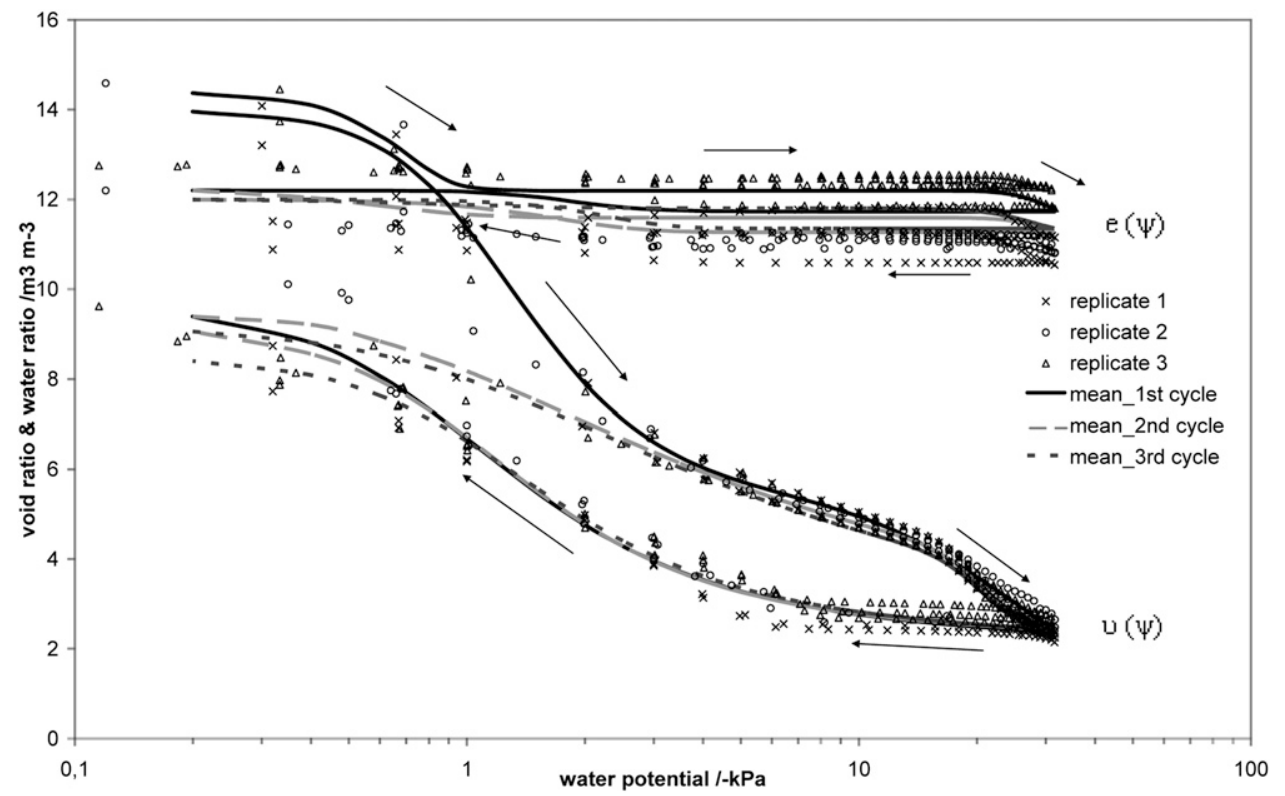

Fig. 4. Water (v) and void (e) ratios as a function of water potential during three drying/wetting cycles between -0.2 and $-32 \mathrm{kPa}$.

Table 2. Fitting parameters and coefficient of determination for $v(\psi)$ mean curve adjustment.

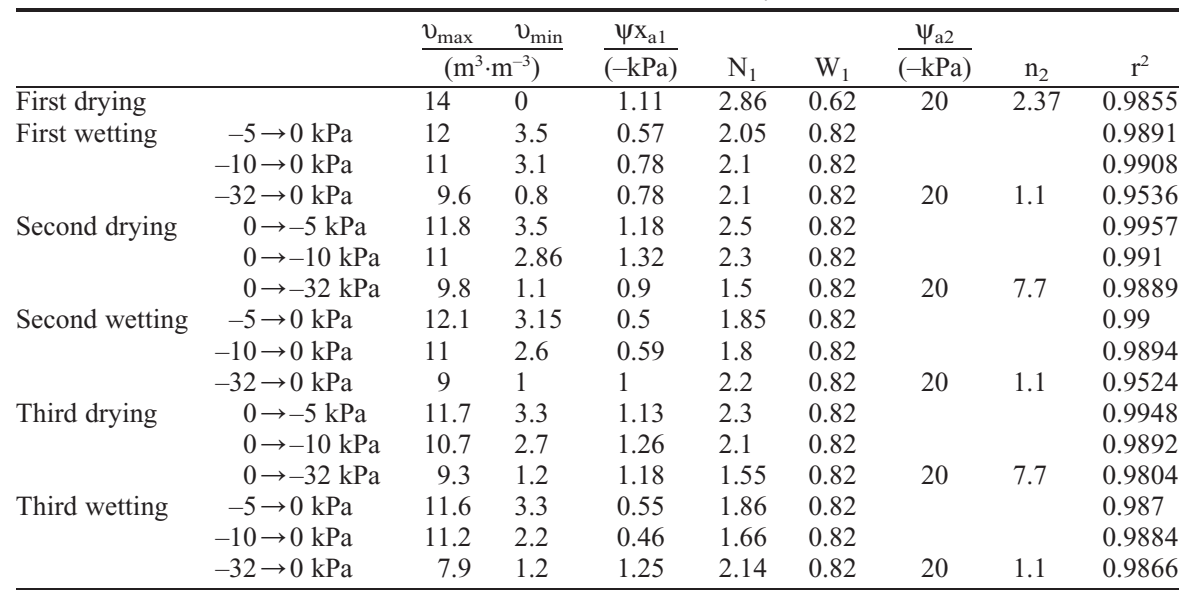

Specifically, for intensities between -0.2 and $-5 \mathrm{kPa}$, as illustrated in Figure 2, the water ratio decreased from 14 to 5.7 and then returned to 11.6 for the first drying/wetting cycle, which indicates that only $80 \%$ of the water was recovered at $-0.2 \mathrm{kPa}$, whereas more than $95 \%$ of the water was recovered during the second and the third cycles. The decrease in water retention properties near saturation was then irreversible for the first cycle but reversible for the following cycles. However, the water ratios obtained after each drying phase for the lowest pressure head were equivalent.

For the higher intensities, between -0.2 and $-10 \mathrm{kPa}$ and between -0.2 and $-32 \mathrm{kPa}$, the general behavior was similar, as already described for -0.2 and $-5 \mathrm{kPa}$, except that the first wetting phase from the lowest pressure head recovered a lower water ratio: $75 \%$ for $-10 \mathrm{kPa}$ and $60 \%$ for $-32 \mathrm{kPa}$.

Regardless of the intensities, the drying/ wetting cycles showed an unclosed hysteretic loop for the first cycle in terms of water retention properties with a gap that varied by $20 \%$ and $40 \%$ of the initial water ratio, whereas the second and third cycles presented a similar and closed hysteretic loop. These measurements showed that peat exhibited marked hysteresis phenomena, in agreement with the results obtained on similar peat-based growing media (da Silva et al., 1993; Naasz et al., 2008).

As for the water ratios, differences in void ratios are shown between the first and the subsequent drying/wetting cycles. For all of the tested intensities, the first shrinkage (and the only one for intensities lower than -10 $\mathrm{kPa}$ ) during the drying phase led to a decrease in volume close to $15 \%$, which occurred between saturation and $-1 \mathrm{kPa}$. The lost volume was almost never recovered during the first wetting process; the first swelling was weak, varying between $1 \%$ and $4 \%$. In contrast to this first cycle, shrink/swell phenomena were very weak (less than 6\%) and reversible for subsequent cycles. As for the water ratios, void ratio evolutions showed an unclosed hysteretic loop for the first drying/ wetting cycle followed by reversible hysteresis phenomena.

Effects of the drying intensity. Changes in water and void ratios showed a quite similar behavior for intensities varying between -0.2 and $-5 \mathrm{kPa}$ and between -0.2 and $-10 \mathrm{kPa}$, with 1 ) a first shrinkage of $\approx 15 \%$; 2) subsequent shrinkages and swellings of $\approx 2 \%$; and 3) an irreversible loss of water after the first cycle that was a little higher for drying up to $-10 \mathrm{kPa}(25 \%)$ than for $-5 \mathrm{kPa}(20 \%)$. Physical behavior differed for drying/wetting cycles with the higher intensity between -0.2 and $-32 \mathrm{kPa}$. An inflection point appeared on void and water ratio curves during each drying phase at $\approx-20 \mathrm{kPa}$ and during each wetting phase at $\approx-5 \mathrm{kPa}$. In contrast to the shrinkage near $-1 \mathrm{kPa}$ during the first drying phase, which is quite irreversible, this second shrinkage phase at $-20 \mathrm{kPa}$ of $\approx 3 \%$ is completely reversible during wetting, but hysteresis phenomena are highlighted because the swelling appeared at a water potential near $-5 \mathrm{kPa}$.

The water ratio curve for an intensity of -0.2 to $-32 \mathrm{kPa}$ exhibited stronger hysteresis phenomena than for intensities varying between -0.2 and $-5 \mathrm{kPa}$ and between -0.2 and $-10 \mathrm{kPa}$. In fact, in contrast to the wetting phases observed after drying of -5 and -10 $\mathrm{kPa}$, which showed an increase in water ratios with that of water potential, the wetting curve from $-32 \mathrm{kPa}$ showed that the water ratios remained almost constant until $-5 \mathrm{kPa}$ and then increased only between $-5 \mathrm{kPa}$ and saturation.

Experimental constraints. The pressure head was measured in the center of the sample, whereas the water content measured by the balance represented the mean value of the whole sample and did not take the vertical moisture gradient in the sample into account. This can lead to discrepancies in the $\Psi(\theta)$ 
relationship because the center of the sample is not necessarily at the potential of equilibrium to the average water content and because the discrepancy may be different whether the ongoing process is drying or wetting. However, in our $5-\mathrm{cm}$ height samples, the divergence of the $\Psi(\theta)$ relationship was not observable for our experiments.

The theoretical air entry pressure of the tensiometer and of the ceramic porous plate used for wetting was $-150 \mathrm{kPa}$. However, the measurement can usually only be performed up to $\approx-70 \mathrm{kPa}$ for the air entry, probably as a result of poor contact between the sample and the porous plate at larger suctions.

The pressure transducers used in this experiment recorded the absolute pressure value. One of them was used to record the atmospheric pressure during the experiments to calculate the differential pressure heads for the samples. The precision of the pressure transmitters was $0.16 \%$ of the measured value. Consequently, when conditions were close to saturation, the uncertainty of the pressure head value was $\approx 0.16 \times 2 \mathrm{kPa}$. Thus, the accuracy of the water retention curve close to the saturation zone was limited.

Volume changes were only calculated from the sample height that is measured by the linear displacement transducer. Consequently, calculation of the volume is based on the hypothesis that shrink/swell phenomena are isotropic, a hypothesis that we actually verified at the end of the experiments.

\section{Conclusion}

We have proposed a new method to simultaneously and continuously determine water retention and shrink/swell properties during several drying and wetting cycles with control of the drying and wetting intensity through matrix potential regulation. This method is relatively simple and fast, allowing a fairly accurate measurement of the physical properties of growing media that vary over time during the same experiment. Nevertheless, this method has several limitations, especially 1) the limited range of water potentials in the case of soil study as compared with growing media for which water is generally managed in this range; and 2) the relatively poor accuracy of pressure head data obtained closed to saturation.

However, the results from this method are encouraging. We show that physical properties are mainly modified by the first drying, resulting in losses of water retention and volume after the first cycle, resulting in an irreversible hysteretic loops, whereas the general physical behavior for the other cycles does not significantly change with reversible hysteresis phenomena. This set-up could then make it possible to evaluate the possible evolutions or physical stability of growing media or soil according to water regime history in the laboratory to manage irrigation accordingly.

\section{Literature Cited}

Boivin, P. 2007. Anisotropy, cracking, and shrinkage of vertisol samples. Experimental study and shrinkage modeling. Geoderma 138:2538

Boivin, P., P. Garnier, and D. Tessier. 2004. Relationship between clay content, clay type, and shrinkage properties of soil samples. Soil Sci. Soc. Amer. J. 68:1145-1153.

Boivin, P., P. Garnier, and M. Vauclin. 2006. Modeling the soil shrinkage and water retention curves with the same equations. Soil Sci. Soc. Amer. J. 70:1082-1093.

Bougoul, S., S. Ruy, F. de Groot, and T. Boulard. 2005. Hydraulic and physical properties of stonewool substrates in horticulture. Sci. Hort. 104:391-405.

Braudeau, E. 1987. Mesure automatique de la rétraction d'échantillons de sol non remaniés. Sci. Sol 25:85-93.

Braudeau, E., J.M. Costantini, G. Bellier, and H. Colleuille. 1999. New device and method for soil shrinkage curve measurement and characterization. Soil Sci. Soc. Amer. J. 63:525-535.

Bronswijk, J.J.B. 1990. Shrinkage geometry of a heavy clay soil at various stresses. Soil Soil Sci. Soc. Amer. J. 54:1500-1502.

Crescimanno, G. and G. Provenzano. 1999. Soil shrinkage characteristic curve in clay soils: Measurement and prediction. Soil Sci. Soc. Amer. J. 63:25-32.

da Silva, F.F., R. Wallach, and Y. Chen. 1993. Hydraulic properties of sphagnum peat moss and tuff (scoria) and their potential effects on water availability. Plant Soil 154:119-126.

da Silva, F.F., R. Wallach, and Y. Chen. 1995. Hydraulic properties of rockwool slabs used as substrates in horticulture. Acta Hort. 401: 71-75.

Durner, W. 1994. Hydraulic conductivity estimation for soils with heterogeneous pore structure. Water Resour. Res. 30:211-223.

Favre, F., P. Boivin, and M.C.S. Wopereis. 1997. Water movement and soil swelling in a dry, cracked vertisol. Geoderma 78:113-123.

Fonteno, W.C., D.K. Cassel, and R.A. Larson. 1981. Physical properties of three container media and their effect on poinsettia growth. J. Amer. Soc. Hort. Sci. 106:736-741.

Gruda, N. and W.H. Schnitzler. 2004. Suitability of wood fiber substrate for production of vegetable transplants. I. Physical properties of wood fiber substrates. Sci. Hort. 100:309-322.
Heiskanen, J. 1995. Physical-properties of 2-component growth media based on sphagnum peat and their implications for plant-available water and aeration. Plant Soil 172:45-54.

Horgan, G.W. and B.C. Ball. 2005. Modelling the effect of water distribution and hysteresis on air-filled pore space. Eur. J. Soil Sci. 56:647654.

Jury, W.A. and R. Horton. 2004. Soil physics. John Wiley \& Sons, Hoboken, NJ.

Michel, J.C., A. Beaumont, and D. Tessier. 2000. A laboratory method for measuring the isotropic character of soil swelling. Eur. J. Soil Sci. 51:689-697.

Michel, J.C., R. Naasz, and N. Montgermont. 2004a. A tool for measuring the shrink/swell phenomena of peat growing media by image analysis. Vol. 2. Proc. 12th Intl. Peat Congr., Tampere, Finland. p. 321-325.

Michel, J.C., P. Morel, and L.M. Rivière. 2004b. The importance of hydric history on the physical properties and wettability of peat. Acta Hort. 644:275-281.

Michel, J.C., L.M. Rivière, and M.N. BellonFontaine. 2001. Measurement of the wettability of organic materials in relation to water content by the capillary rise method. Eur. J. Soil Sci. 52:459-467.

Naasz, R., J.C. Michel, and S. Charpentier. 2005. Measuring hysteretic hydraulic properties of peat and pine bark using a transient method. Soil Sci. Soc. Amer. J. 69:13-22.

Naasz, R., J.C. Michel, and S. Charpentier. 2008. Water repellency of organic growing media related to hysteretic water retention properties. Eur. J. Soil Sci. 59:156-165.

NF EN 13041. 2000. Amendements du sol et supports de culture-Détermination des propriétés physiques-Masse volumique apparente sèche, volume d'air, volume d'eau, valeur de rétraction et porosité totale. Association Française de Normalisation, Paris, France.

Peng, X. and R. Horn. 2005. Modeling soil shrinkage curve across a wide range of soil types. Soil Sci. Soc. Amer. J. 69:584-592.

Schmilewski, G. 2009. Growing medium constituents used in the EU. Acta Hort. 819:33-46.

Tariq, A.U.R. and D.S. Durnford. 1993. Soil volumetric shrinkage measurements-A simple method. Soil Sci. 155:325-330.

Valat, B., C. Jouany, and L.M. Rivière. 1991. Characterization of the wetting properties of air-dried peats and composts. Soil Sci. 152: 100-107.

Van Genuchten, M.Th. 1980. A closed-form equation for predicting the hydraulic conductivity of unsaturated soils. Soil Sci. Soc. Amer. J. 44:892-898

Wallach, R., F.F. da Silva, and Y. Chen. 1992. Hydraulic characteristics of tuff (scoria) used as a container medium. J. Amer. Soc. Hort. Sci. 117:415-421.

Warrick, A.W. (ed.). 2002. Soil physics companion. CRC Press, Boca Raton, FL. 